\title{
Dispositions and Skills: An Argument for Virtue Ethics against Situationism
}

\section{Janina Angeli M. Magundayao}

\begin{abstract}
Virtue ethics faces a critique from the situationism regarding the its emphasis on robust and stable dispositions that supposedly determine one's behavior. According to situationists, virtuous dispositions fall short of the expected 1.0 correlation between virtue possession and behavior manifestation, as evidenced by the results of social psychology experiments which show that situational factors can determine one's behavior more than dispositions can. John Doris, the situationists' champion, recommends that we abandon our efforts in cultivating virtue in favor of honing our situational sensitivity. This essay responds to the critique by showing that the expected correlation between dispositions and behavior rests on a conceptual confusion surrounding the word "disposition." In order to avoid this confusion and to recover ancient Greek insights on virtue, the essay proposes that we view virtue as analogous to a skill that also involves intellectual and motivational structures, not merely dispositions. The skill analogy implies that we should not give up on cultivating virtue, as virtue is not static but constantly developing with experience.
\end{abstract}

Keywords: Virtue ethics, situationism, dispositions, virtue as a skill

\section{Introduction}

$\mathrm{V}$ irtue ethics emphasizes on the agent's settled patterns of choices and actions, which draw from robust dispositions. These robust dispositions are aimed at the good, in view of an individual agent's life as a whole. However, the emphasis on one's character as a whole, which influences her choices on how to act in given situations, is put into question by situationists, as championed by John Doris and supported by others like Gilbert Harman and Lee Ross and Richard Nisbett. One of the main critiques of situationism against (Aristotelian) virtue ethics is that it makes pragmatic claims about people's

(c) 2013 Janina Angeli M. Magundayao http://www.kritike.org/journal/issue 12/magundayao june2013.pdf ISSN 1908-7330

\section{(cc) BY-NC}


behavior without accounting for available empirical literature: its account regarding an individual's character is "empirically inadequate." Empirical results from social psychology show that situational factors have a more significant effect to overt behavior than an individual's possession of certain character traits. Situationists say that we have become fond of attributing possession of a character trait to a person when we see her perform a certain kind of behavior when in fact, character traits have less to do with one's behavior than situational factors have. This leads situationists to suggest that we should reconsider the role that we give to personality traits in terms of explaining and predicting people's behavior. ${ }^{2}$

If situational variables can influence a person's behavior more than her character traits can, should we not abandon our efforts to cultivate character in favor of improving our sensitivity to situational factors? $?^{3}$ This is the kind of question that a situationist would ask of any virtue ethicist, and this is the question that I hope to address here. Without going ahead of ourselves, I intend to show that we should not abandon our efforts to cultivate virtue. I propose in this paper that we look at virtue not as robust dispositions in themselves, but as a skill that can and should be cultivated. For some people, this skill analogy of virtue would seem old-fashioned and uninteresting. The ancient Greeks, primarily Aristotle and the Stoics, have already drawn parallels between virtues and skills, but very few modern thinkers have followed this line of thought and on top of that, none of those who followed found it necessary to fully address the situationist critique. ${ }^{4}$

${ }^{1}$ John Doris and Stephen Stich, "As a Matter of Fact: Empirical Perspectives on Ethics," in The Oxford Handbook of Contemporary Philosophy, ed. Frank Jackson and Michael Smith (New York: Oxford University Press, 2005), 118.

${ }^{2}$ John Doris, "Persons, Situations, and Virtue Ethics," Nous 32 (1998), 513. Also in John Doris, Lack of Character: Personality and Moral Behavior (New York: Cambridge University Press, 2002), 108-9.

${ }^{3}$ Doris, "Persons, Situations, and Virtue Ethics," 515.

${ }^{4}$ One of the main proponents of this skill analogy today is Julia Annas. She draws her commitment to this analogy from the ancient Greeks themselves (Annas gives an informative summary on this in her book, The Morality of Happiness, published in 1993). Most ancient accounts of the analogy emphasize on the need for an "intellectual structure" for both virtues and skills: both require that the person trying to be virtuous or skillful be able to understand what it is that she is trying to do and what it is that she is trying to achieve. The ancient Greeks all agree that virtues are analogous to skills: Aristotle and the Stoics emphasize on the practical aspect of skills: like skills, virtue has to be practiced. It is through our past experiences that we are able to form our robust dispositions by habituation. Annas says the particular ancient Greek account that she subscribes to is the "Socratic" account that prioritizes the intellectual structure of skills. Despite the consensus, ancient accounts differ from each other because of the extent to which they take their analogies: is virtue only like a skill or is it a skill per se? This is an important issue to address, but it has to be dealt with elsewhere. For the purposes of this essay, I shall be content with saying that virtue is better understood as a skill, and reasons for believing this will be given later. Another contemporary proponent of the skill analogy would be Matt Stichter, who wrote two pieces of literature on it in 2007: a doctoral dissertation entitled The Skill of Virtue, and a short article entitled, Ethical Expertise: The Skill Model of Virtue. He also wrote another article in 2011, entitled Virtue, Skills, and Right 
Despite the seeming lack of modern interest in this analogy, I still find it important because it reminds us that virtues are not just robust dispositions, they are developing dispositions that often require intelligence and motivation from the agent. If we take the analogy to heart, we should understand that virtue lies not solely in the consistency of behavior, but the consistency of the individual's choices to constantly cultivate her character. Virtue is about trying to achieve excellence, and the skill model provides that avenue for improvement of character that is not available when we construe virtue as robust dispositions.

The success of my efforts in this paper can be assessed if I am able to convince the reader that the efforts spent in cultivating our character for the better are not futile, despite the situationist claim that our behavior is influenced by situational factors. To make this point, this paper shall then be divided into two major sections. First, I shall go through a discussion of situationism and its arguments against virtue ethics. I will argue that we might have been conceptually confused about our notion of disposition; and the situationist critique is most salient only because the account of virtue ethics that it attacks is based on this confusion. In the second section, I propose that we use the term "skills" to refer to virtue, not only to prevent further confusion, but also to recover the ancient notion of virtues as "active and developing dispositions"s that require intelligence. With this two-fold argument, I hope to show that we need not give up on cultivating virtue, even if our behavior can be affected by situational factors.

\section{Situationism, Dispositions and the High Bar Argument}

The nature of the situationist critique of virtue ethics is not simple. Situationism per se has two different, albeit related, strands: psychological situationism and philosophical situationism. According to Nancy Snow, both strands of situationism refer to the same empirical literature, but they draw different claims from it. ${ }^{6}$ Psychological situationism questions the personality theories whose structures suggest that people have "global" or robust personality traits. By global and robust, we mean personality traits that are cross-situationally consistent and temporally stable. Under the globalist personality structure, saying that a person possesses a certain global trait, like honesty for instance, means that she has to manifest this trait in her behavior in different situations that call for it

\footnotetext{
Action. Stichter develops his account from the Dreyfus model of skill acquisition, which has five stages: novice, advanced beginner, competent performer, proficient performer, and finally, the expert. In his dissertation, Stichter claims that his analogy is similar to Aristotle's because of the emphasis on habituation and experience (pp. 36-42).

${ }_{5}^{5}$ Julia Annas, Intelligent Virtue (Oxford: Oxford University Press, 2011): 7.

${ }^{6}$ Nancy E. Snow, Virtue as Social Intelligence: An Empirically Grounded Theory (New York and London: Routledge, 2010), 2-3.
} 
(e.g., filing for taxes, taking an exam, dealing with a business partner, etc.), and has been doing so for quite some time.

However, evidence from social psychology show that this globalist understanding of personality is "empirically undersupported:" people do not have cross-situationally consistent, global traits. In one of their experiments, Hartshorne and May measured the tendencies of school children to display deceptive and honest behaviors in varying situations. They found out that while the children's behavior are consistent, this consistency is dependent on the similarity of the situations that the children find themselves in. ${ }^{7}$ For instance, school child Dorothy has displayed the tendency to cheat on her exams by means of copying from answer keys. Even though we have seen her cheat this way on many occasions, this does not mean that she also cheat using a different method on a different kind of test. Hartshorne and May observed that the correlation of their subjects' cheating behavior using the same method of cheating is high at 0.70 , but the correlation of cheating behavior using two different methods is not very strong at $0.29 .{ }^{8}$ Thus, if we would like to prevent Dorothy from cheating on her tests, we should not give her the same kind of test where we have seen her cheat. Dorothy's history of cheating will only be more likely to repeat if she is given the same kind of test over and over. This, however, does not say anything about how Dorothy would behave if she were given a different kind of test. Thus, Dorothy's cheating behavior does not draw from her "cheating" personality, but from the situation that she is in.

Philosophical situationists pick up on this critique of the global traits and apply it to virtue ethics by problematizing not only cross-situational consistency of behavior, but also the personality structure's evaluative integration. Analogous to the traditional claim on the unity of virtues, the evaluative integration of personality suggests that the possession of a certain trait, like honesty, most likely entails the possession of similarly-valenced traits. ${ }^{9}$ Thus, if Mark has shown himself to be honest for quite some time, it can also be expected that he will be loyal and just. However, Doris puts evaluative integration into question by citing the case of the some Auschwitz doctors during Nazi Germany. These doctors were regarded as honest, decent, and compassionate to the point of trying to save the lives of some prisoners; but the next day, they are the ones who make orders for the mass murders and the inhuman experimentation on the prisoners. If personality is really integrated, then contradicting behaviors should not exist within the same person.

\footnotetext{
${ }^{7}$ Hugh Hartshorne and Mark May, Studies in the Nature of Character, vol. I: Studies in Deceit (New York: McMillan, 1928): 382-3, quoted in Doris, Lack of Character, 63-4.

${ }^{8}$ Ibid.

${ }^{9}$ John Doris, Lack of Character: Personality and Moral Behavior (New York: Cambridge University Press, 2002), 22-23.
} 
As an alternative to the globalist perspective on character, Doris suggests that we view character as fragmented: the traits that we have are temporally stable, but they are local and highly situation-specific. ${ }^{10}$ This means that we should not settle at calling someone honest since this implies a broad trait-we have to be more situation-specific: Bruno is honest-when-dealing-with-clients or Bruno is courageous-when-sailing-with-friends-in-bad-weather. Our fragmented characters allow dissimilar traits to co-habit in the same person, so even if Bruno has the local traits of honesty and courage mentioned above, it will not be a contradiction for him to be dishonest or cowardly other aspects of his life. ${ }^{11}$ The consistency requirement for local traits, as Doris puts it, is this: 'one can expect the 'usual' [behavior] only in the usual circumstances." 12

Like their psychological situationist counterparts, philosophical situationists seem to construe the possession of traits (and virtues) as having robust dispositions. From a virtue ethical standpoint, this is true, since virtues really are robust dispositions: they stem from "firm and unchangeable character,"13 and we can expect some degree of reliability from people whom we think have these robust dispositions. However, the term disposition seems to create a conceptual confusion: the ancient definition of disposition is different from its contemporary definition. I think it is important for us to clear up this confusion because it can help us determine how salient the general situationist critique against virtue ethics really is.

Our contemporary definition of disposition comes from Quine's definition of the term as a subjunctive conditional statement that expresses "built-in, enduring structural traits" of certain objects. ${ }^{14}$ This definition has developed to what is known as the "simple conditional analysis" (SCA). ${ }^{15}$ Translating this

\footnotetext{
${ }^{10}$ Ibid., 64.

${ }^{11}$ The examples of these local and situation-specific traits are also from Doris, Lack of Character.

${ }^{12}$ Ibid., 65.

${ }^{13}$ Aristotle, "Nicomachean Ethics," 1105a27-b1, in Readings in Ancient Greek Philosophy: From Thales to Aristotle, eds. S. Marc Cohen, Patricia Curd and C.D.C. Reeve (Indianapolis/Cambridge: Hackett Publishing Company, Inc., 1995), 677.

${ }^{14}$ Willard Van Orman Quine, Word and Object (Cambridge: Massachusetts Institute of Technology Press, 1960), 222-3. The common example to explain this definition of disposition is that of the fragility of a piece of glass. A piece of glass is inherently fragile, but its disposition to show this fragility by breaking is not manifested if the condition that calls for it, the striking of the piece of glass, does not take place. It is the same thing with virtue and personality traits: they can be possessed by people, but can only be manifested when the situations that call for it arise.

${ }^{15}$ Sungho Choi, "Dispositional Properties and Counterfactual Conditionals," in Mind 117 (2008), 796. The issue of dispositional properties is a debated topic in metaphysics today, and there is a consensus that the SCA is no longer a viable means of analyzing dispositional properties. Other conditionals have been developed in its place, including the reformed counterfactual (or conditional) analysis (RCA). Many metaphysicians advocate this, but for the main purpose and the
} 
conditional to character-relevant terms, we can say that a person has the disposition to exhibit a particular behavior in response to a situation that calls for it, if and only if:

(1) if she were to be in that kind of situation at any given time;

(2) and she exhibits that particular behavior.

This means that we can only attribute possession of a character trait (or a virtue) when we see it manifested in overt behavior. Thus, Cary can only be said to possess the trait of compassion, and be predisposed to help others, only when she actually helps others in response to finding herself in a situation where someone needs help. As an added requirement for virtue, one has to act in accordance with her virtue reliably across repeated iterations of "relevantly similar" situations. If we view virtues as dispositions in this sense, as dispositions that lead to a certain kind of action when the person who possesses it finds herself in a specific kind of situation, then it becomes highly susceptible to the situationist "high bar" argument, a term coined by Edward Slingerland to refer to what he thinks is the "core claim of situationists." 16

Slingerland puts the argument very simply: "virtue ethics demands a correlation between virtue possession and actual behavior of close to 1.0 and that anything short of that is a fatal problem," ${ }^{17}$ but I feel the need to expand it. Since virtues are dispositions, it is implied that it should have a near 1.0 correlation between virtue or trait possession and actual behavior. The behavior that the agent is predisposed to do is inherent in the disposition itself, it just needs to be triggered by the situation to be manifested. This means that for Jane, a person we have seen to be compassionate before, to really possess the trait of compassion, she would have to manifest that trait in her overt behavior in most instances where it seems needed, like helping a cat get off a tree or helping an elderly person cross the street. If we are to subject Jane to the Milgram experiment, ${ }^{18}$ and find out that she obeyed the experimenter in shocking an innocent learner with a deadly voltage, we can say that Jane failed to be compassionate in that situation. From our standpoint as observers, we can say that Jane has not acted virtuously in that situation.

limitations set by this essay, we shall stick to the SCA. The exact definition of the SCA that is given by Choi is:

"Something $x$ has the disposition at time $t$ to exhibit manifestation $m$ in response to being situated in stimulating circumstance $c$ iff, if $x$ were to be situated in $c$ at $t$, it would exhibit $m$." (Ibid.)

${ }^{16}$ Slingerland, Edward, "The Situationist Critique and Early Confucian Virtue Ethics," in Ethics 121 (January 2011), 14.

${ }^{17}$ Ibid.

${ }^{18}$ Stanley Migram, Obedience to Authority: An Experimental View (New York: Harper and Row, 1974).

(C) 2013 Janina Angeli M. Magundayao

http://www.kritike.org/journal/issue 12/magundayao june2013.pdf

ISSN 1908-7330 
The hasty virtue ethicist can perhaps say that Jane, with the rest of Milgram's subjects, is not yet fully virtuous to rationalize her acting poorly poorly in that situation. However, the more careful virtue ethicist would also have to account for the empirical data from the studies done by Walter Mischel. He found out that relationship between the manifestation of people's personality traits in behavior rarely exceeds 0.3 (also known as the "personality coefficient"). ${ }^{19}$ Mischel dismissed this value as "weak," ${ }^{20}$ but only in comparison to the 1.0 expectation. ${ }^{21}$ The dismissal of the personality coefficient as weak and negligible seems to have made the situationist critique of virtue ethics stronger.

Slingerland's response to this high bar argument is two-fold: he "lowered the bar of requirement" for virtue and "enhanced our capacity to jump over the bar" by developing ideas from Confucian virtue ethics. ${ }^{22} \mathrm{I}$ believe this to be a good response. However, it seems to me that the high bar argument is founded upon a conceptual confusion regarding the word disposition. Implied in the contemporary definition is a one-to-one correspondence between the disposition per se (the possession of character traits) and the predisposed manifestation of the outcome (the behavior that supposedly ensues from it). The problem with this

${ }^{19}$ Walter Mischel, Personality and Assessment (New York: John J. Wiley and Sons, 1968), 77-8. Quoted In Doris, Lack of Character, 63. Also in Slingerland, “The Situationist Critique," 7-8.

${ }^{20}$ Slingerland dedicates a subsection of his paper to discuss the statistical significance of this 0.3 correlational value. He says that small correlational values, like the personality coefficient, can represent significant correlative effects between the factors it relate (pp. 6-9). For example, a correlation value of 0.3 is significant enough for us to be able to predict the outcome of dichotomous situations, "65-70 percent of the time" (p. 9). He also claims that the correlation of situational effects with overt behavior is also at $0.2-0.3$ "when translated to a common metric" as the personality coefficient. "If a correlation of 0.3 is genuinely so weak as to be negligible," says Slingerland, "then nothing predicts behavior" (p. 8). John Sabini and Maury Silver, "Lack of Character? Situationism Critiqued," Ethics 115 (2005), was also quoted by Slingerland regarding this statistical issue. Sabini and Silver suggest that correlational values are not as straightforward as presented when applied to situations, and this is also true of the personality coefficient. Many factors can affect an individual's observed behavior, and these factors can "erode the correlation" (pp. 542-44). They cite as an example the likelihood of someone cheating on an exam is not dependent solely on one's possession of the trait of dishonesty. One's intelligence, preparedness to take the exam and biases regarding the subject matter, among others, can also affect one's decision to cheat or not.

${ }^{21}$ Slingerland (p. 14) says that situationists are not really denying the 0.3 correlation value of any predictive power, only that this value falls far too short of the expected 1.0 correlation between virtue possession and manifested behavior.

${ }^{22}$ Slingerland, "The Situationist Critique," 4. He "lowered the bar" by acknowledging the fact that we do have personality traits: "people...have the capacity to jump" over the bar, but we need to boost or enhance this capacity so that we can actually clear the bar. In Confucian virtue ethics, Slingerland says, one's natural capacities or dispositions can be "extended" by analogy so that they can be used as bases for new capacities and dispositions that can learned. By extension, we can make global what situationists regard as local traits, and all this through the help of a moral exemplar. Slingerland gives as example the case of King Xuan of Qi who was guided by Mencius in extending his virtue of compassion for sacrifice oxen to compassion for his human subjects (pp. 17-19). 
contemporary definition is that it assumes that behavior can only be determined by our possession of dispositions alone, and not in conjunction with any other factors. ${ }^{23}$ But if we go back to the ancient Greek notion of virtues as robust dispositions, we will find that they use the word very differently from how we use it today.

We come to know virtue as disposition because it is the most common English translation of Aristotle's notion of virtue as hexis or a "stable state of character." 24 The "stable state of character" of a person has been acquired through the process of habituation, or the repetition of similar activities. ${ }^{25}$ The word habituation here is often misunderstood as well, owing to the modern connotation of acting from habits as acting in a seemingly automatic fashion. In our everyday usage of the term, acting from habits mean that one is acting mechanically from temporally stable routines or patterns of behavior. Since, we act from our habits passively, it becomes hard to break and is, in that sense, stable. But this is not what acting from a "stable state" means to Aristotle. For him, a state is a condition that arises from the soul that involves reason; it is different from a feeling or a capacity. ${ }^{26}$ We cannot be praised or blamed for having (or not having) feelings and capacities, because these do not involve a decision. Acting from a stable state of character, to Aristotle, means acting from virtue: it involves a decision-the choice to act in a way that is coherent with our past decisions. ${ }^{27}$ Since it involves a

${ }^{23}$ In my opinion, this contemporary definition of dispositions bifurcate and polarize the debate we have at hand. To be fair to the situationist position (both the psychological and the philosophical strands), they do recognize that behavior is a function of both the person and the situation (Kurt Lewis, as cited by Lee Ross and Richard Nisbett, The Person and the Situation: Perspectives of Social Psychology (USA: Mc-Graw-Hill, Inc., 1991), 9). This idea is also expressed by Daryl J. Bem and D.C. Funder, "Predicting More of the People More of the Time: Assessing the Personality of Situations," Psychological Review 85 (1978), 485-6, in Doris, Lack of Character, 26. Although they recognize the joint influence of situations and personality in people's behavior, situationists, particularly Doris, still recommend that we abandon character cultivation in favor of improving our situational sensitivity (in "Persons, Situations, and Virtue Ethics," 515. This recommendation seems to contribute to the polarization of the debate, and it seems to me to be a stumbling block in our own understanding of human behavior in general.

${ }^{24}$ Aristotle, Nicomachean Ethics 1106a10, 678.

${ }^{25}$ Ibid., 1103b20-25, 673-4.

${ }^{26}$ Ibid., 1103b20-1104a 10

${ }^{27}$ I use the phrase "coherent with her past decisions" to mean what Aristotle would normally mean by "acting in the same way," or habituation. This is to avoid falling into another conceptual confusion regarding the Aristotelian and contemporary usage of the terms, habits and habituation. By habituation and "habits of choice," Aristotle means the repeated choice to perform virtuous acts, as stated by Julia Annas in The Morality of Happiness (Oxford: Oxford University Press, 1993), 51 and 54. It does not imply passive action on the part of the individual, but an active choice to act in that manner. At times, I will use "settled patterns of choice" to mean the same thing. 
choice and also reason, we can be held liable for our actions and thus, be praised and blamed for it. ${ }^{28}$

As such, it is our choice to continue to act in a certain way that makes our dispositions, not the other way around. Annas also says that we should not think of dispositions as causal forces that influence our choice of action, but as the "increasing effectiveness of [our] rationality." 29 Virtuous dispositions are "active" because they involve our repeated choice to act in the way that is coherent with her past choices, and they are "developing." ${ }^{30}$ I would like to suspend the discussion regarding the "developing" aspect of virtuous dispositions, because this would lead us abruptly to the point of the next section. What is important to realize for now is that our confused concept of disposition has led us to a mistaken concept of virtue. The possession of virtue does not mean that people mechanically act from these dispositions; it only means that people actively choose to act in accordance to that settled pattern of choice. Thus, it is the agent's pattern of choices that should be stable and reliable, if she were to be considered virtuous.

The conceptual confusion regarding the word disposition has now been cleared. This leads me to two questions. First, if the high bar argument of the situationists is founded on this conceptual confusion, and the clearing up of the confusion lets us see that our contemporary notion of virtue as 1.0 correlationthe notion most salient to the situationist critique-is different from the ancient notion of virtue, does this mean that the situationist critique should not bother us anymore? My short answer is no. To be fair to Doris, he did recognize that "virtues are not mere dispositions but intelligent dispositions, characterized by distinctive patterns of emotional response, deliberation, and decision..." (sic). ${ }^{31} \mathrm{He}$ recognizes that virtues as dispositions are not entirely mechanistic, they involve the agent's reasoning as well, but towards the end of that sentence, he again emphasizes on overt behavior. People's choices may be influenced by these psychological and cognitive units-our emotional responses and deliberative capacities are also aspects of our personality—but these choices are still reflected in overt behavior. If the deliberative capacities of the agent cannot make her act virtuously, then there seems to be a problem for virtue ethics. ${ }^{32}$ It may have been

${ }^{28}$ Aristotle, Nicomachean Ethics 1107a, 680

${ }^{29}$ Annas, The Morality of Happiness, 51.

${ }^{30}$ Annas, Intelligent Virtue, 7.

${ }^{31}$ Doris, Lack of Character, 17.

${ }^{32} \mathrm{Ibid}$. Doris finds it problematic that personality theorists are too lenient with their behavioral criteria: "if a habit is contrary to a trait does not undermine the attribution, it is hard to see what possibly could” (p. 26, sic). Doris's concern is trait attribution and behavior prediction. The former is not my main concern here, and Doris raises a valid point regarding the importance of behavior prediction, after all most of our social interactions and institutions are based on our predictions of each other's behavior. However, I find it a bit problematic that he talks about "habit" 
the case that Jane, our hypothetical character earlier, has the trait of compassion, but she did not choose to behave in a way that is coherent with that trait at the time of the experiment. Milgram says that his subjects might have viewed themselves as agents, not in the sense that they can effect change in their environment, but as agents in the sense that they are "carrying out another person's wishes," i.e., the experimenter's wishes. ${ }^{33}$ Situational factors then prove to not only to swamp our personality dispositions, but also our recognition that we are acting on our own choice. Thus, the situationist critique is still alive and well.

The second question is more like an issue tangent to the concerns of this paper, but in my opinion is worth raising here. I want to ask whether the analogy of virtue with personality traits is warranted. If virtues, as dispositions, are not causal forces but choices to act in the same way, then it does not seem to be analogous with personality traits. Personality traits can be strong causal forces that affect our behavior, as in the case of the traits of people with maladaptive personality structures. People with attention deficit disorder, for example, do not choose their attention spans to be really short: it is a trait that comes with their personality structure, but it causes them to behave in a way that would seem to others as erratic and impulsive. They tend to hop from one thing to another, leaving most of the things they started unfinished, but doing so is not an active choice on their part. However, they can choose to do something about these traits so that its "causal power" will not be as magnified when unmitigated. I would like to stop pursuing this line of thought for now, because I am not in the position to talk about personality structures professionally, but I would like to point out that people may not have chosen what kinds of traits they will have, but they can choose to do something about it. People can do better if they choose to, but one has to arrive at that choice and to constantly make that choice.

In this section, I tried to establish that our contemporary understanding of virtue as a stable disposition might have been mistaken. Our contemporary notion does not correspond to the notion of disposition as hexis in the Ancient Greek sense. For the ancients, disposition is a product of one's repeated choice to

when the basis for the situationist critique are social experiments that happened to the subjects only once in their lives. Rachana Kamtekar, in her article Situationism and the Content of our Character, raises the same point in a footnote regarding the methodology of the oft-cited situationist experiments (466). Kamtekar says that the experiments did not track behavior across situations and that the findings are only based on one occurrence of the experiment. She recognizes that while there are experiments that track behavior cross-situationally (such as the Hartshorne and May experiment mentioned in the early part of this section), the findings drawn from these were based on group performance and not individual performance. Doris, in Lack of Character, did address this methodological critique prior to Kamtekar's writing, but the reasons he gave are practical and therefore, theoretically and philosophically uncontestable. Doris says that this limitation in their methodology is due to "logistical and financial reasons," because "one controlled observation is cheaper than many" (71).

${ }^{33}$ Milgram, Obedience to Authority, 133. 
act in a way that is coherent with her past decisions. On the contrary, our contemporary parlance seems to understand dispositions the other way around: our dispositions cause us to act in a certain way. I believe this confusion is at the root of the situationist high bar argument, which expects a 1.0 correspondence between the possession of virtue and its manifestation in behavior. Empirical data show that the average correlation between trait possession and behavior is lower, at 0.3 . The word disposition can mislead us into understanding the possession of virtue as having automatic behavioral responses to situations. To avoid this confusion, I propose that we use the term skill instead. When we say skill, we are not referring primarily to something robust and unchanging; we are referring to something that requires one's active participation and intentionality. This, to me, seems to be the better understanding of what virtue is. The cultivation of virtue and the development of skill are both teleological: the former, aiming at the good life, and the latter at excellence or expertise; and both require an intellectual structure for its cultivation.

\section{Virtue vis-à-vis Skill}

Some virtue ethicists respond to the situationist critique by saying that virtue ethics is not concerned with producing right action per se, but with guiding us on how to achieve the good life. ${ }^{34}$ Unlike situationists whose interest in dispositions is behavior prediction and trait attribution, virtue ethicists are interested in dispositions because of its emphasis on forming "settled patterns of choice" that help us achieve our final end. ${ }^{35}$ Annas points out that there are two different conceptions of the final end for the ancient Greeks: telos and skopos. ${ }^{36}$ She says that this difference seemed unimportant for Aristotle, because he uses these terms interchangeably; but the Stoics are quite particular with this distinction: virtue is found not in the skopos, but in the telos. The skopos refers to the target or aim of an action, while the telos refers to the things that the agent does to achieve that aim. If we translate this into character terms, this distinction means that the virtue of a person lies not in the action she ends up doing, but in what she does to decide on her course of action.

This is often the case when we are trying to develop a skill. The goal of every skill development process is expertise, but reaching that goal does not happen instantaneously. We acquire a skill through practice-it involves a

\footnotetext{
${ }^{34}$ Annas, Morality of Happiness, 42-46. This idea is also expressed in Julia Annas's "Being Virtuous and Doing the Right Thing," in Proceedings and Addresses of the American Philosophical Association 78:2. Also in Maria W. Merritt's "Virtue Ethics and the Situationist Personality Psychology," in Ethical Theory and Moral Practice 3 (2000), 371.

${ }^{35}$ Annas, The Morality of Happiness, 51.

${ }^{36}$ Ibid., 34.
} 
repeated choice to be coherent with past decisions-but development does not happen when we are able to choose coherently without experiencing any difficulty. ${ }^{37}$ Furthermore, some skills emphasize the need to develop dispositions so that the accompanying skill can be performed well. However, we should not think of skills as mere dispositions because to do so would be deflationary: deflationary in the sense that dispositions, even dispositions to act in a coherent way, are static and passive: they are there, but they are only waiting to be triggered before they can be manifested in overt behavior (as in the idea of dispositions in the contemporary sense). According to Robert McCrae and Paul Costa, our personality traits do not change substantially over the course of one's lifetime. ${ }^{38}$ Thus, if we have people like Bruno who only have "local" traits, then they are most likely to be stuck with it for the rest of their lives. What's worse about this is that the kind of behavior that ensues from these personality traits would also remain the same. If Bruno wants to cultivate his character, then he has to rely on a something other than his personality dispositions and habits. Settled patterns of acting and choosing cannot, in themselves, make people better.

Skills, on the other hand, are dynamic and complex. ${ }^{39}$ Skills require constant practice and active effort from the agent in order to develop. The knowledge involved with skills is empirical since it requires experience to prosper. The good thing about developing a skill is that it does not discriminate between

${ }^{37}$ This is the reason why we are advised to take on challenging exercises that push our skills to its limits when we are trying to better our skills. The difficulty we experience in tackling such challenges helps us grow by giving us new experiences to learn from, rather than settling for the usual experiences that we encounter. Challenges and new experiences thus broaden our horizon regarding the practice of our skills, which in turn, foster development.

${ }^{38}$ Robert R. McCrae and Paul T. Costa, Jr., Personality in Adulthood: A Five Factor Theory Perspective $2^{\text {nd }}$ ed (New York and London: The Guilford Press, 2003), 108.

${ }^{39}$ The fact that there are many types of skills is obvious, so we must be careful in our skill analogy of virtue. Skills are generally task oriented. In his book, Dimensions of Expertise, Christopher Winch says that some skills are highly task-specific: the knowledge derived from it may not be applicable to other tasks (e.g. a sommelier's expertise cannot be translated to expertise in physical activities or even to expertise in cooking). On the contrary, there are also some skills whose knowledge can be suited for other tasks (i.e. mathematical expertise can be used outside of arithmetic per se, it can be applied to other fields of knowledge like computer science, engineering, military science, and even logic. Where analytic precision is needed, good mathematical skills can go a long way). If we look at virtuous dispositions as skills that bring about behavior (as in the contemporary understanding of dispositions), then we can perhaps say that virtue is a highly taskspecific skill: it is not cross-situationally transferable. However, if we look at virtue as a kind of cognitive skill in the form of intelligence-a point I would like to elaborate in a different essay and a point similar to what Nancy Snow points out in her book, "Virtue as Social Intelligence" - then we can probably say that virtue is a skill whose knowledge can be translatable to other fields. At first glance, it may seem like I am making a reference to the unity of the virtues thesis: intelligence, phronesis, is that which unifies the virtues from the agent's point of view and that which allows the agent to make judgments about what is good in particular aspects of her life (in Annas, the Morality of Happiness, 75-6).

(C) 2013 Janina Angeli M. Magundayao

http://www.kritike.org/journal/issue 12/magundayao june2013.pdf

ISSN 1908-7330 
the kinds of experiences that ensue from it: whether the experience ended well or badly, we learn from it. Skills are not like patterns of choice that become "depreciate" if one breaks the pattern; skills still get developed even when one commits a mistake. We do, especially the reflective ones, learn from our mistakes, and sometimes committing a mistake is the starting point for a person to better herself.

I am not saying that we should deliberately make mistakes in order to "speed up" the process of becoming virtuous; I highly doubt that the process can be sped up. I am only saying that mistakes, or instances where one acts "out of character," can be starting points for the development of one's character. ${ }^{40}$ Going back to the case of compassionate Jane, although she may have acted out of character when she shocked the learner from the Milgram experiment, she can still learn from this negative experience by either reflecting on it, or by receiving feedback from others. If Bruno tells Jane that what she did to the learner in the experiment was inhumane and uncharacteristic of her trait of compassion, or if Jane realizes this on her own, then she can deliberate on different strategies to help her act more compassionately when she finds herself in a similar circumstance in the future. In this case, Jane's disposition to be compassionate was not undermined by her negative experience, but rather given the opportunity to develop.

Christopher Winch says dispositions and skills usually go together, but skills should not be reduced to dispositions, because skills involve a more specific kind of knowledge. ${ }^{41}$ He follows the distinction that Gilbert Ryle makes between the knowing how and the knowing that, ${ }^{42}$ and goes on to say that skills are more involved with the knowing how, than the knowing that; and that the former cannot be reduced to the latter. ${ }^{43}$ Thus, if we are to say that Bruno possesses the skill of sailing a boat, we should not be content in saying that Bruno knows that sailing a

\footnotetext{
${ }^{40}$ This point was mentioned in passing by Linda Trinkaus Zagzebski, Virtues of the Mind: An Inquiry into the Nature of Virtue and the Ethical Foundations of Knowledge (Cambridge: Cambridge University Press, 1996), 123.

${ }^{41}$ Christopher Winch, Dimensions of Expertise: A Conceptual Exploration of Vocational Knowledge (London and New York: Continuum, 2010), 39-40.

${ }^{42}$ Ryle's discussion of this distinction is presented in his article, "Knowing How and Knowing That," which was published in 1946. According to Winch a chapter with the same title appears in Ryle's book, The Concept of Mind (1949).

${ }^{43}$ Winch, op cit., 39-40. The distinction between these two kinds of knowing is a another debate in itself. Winch dedicates a whole chapter of his book to discuss it. Knowing that and knowing how usually go together, but the knowing how is not reducible to the knowing that because the knowing how is that which provides an explanation for (or an account for) the other kind of knowing (p. 36). In the next two chapters of his book, Winch focuses on the knowing how because "an agent's knowing how to do something...typically results to an action of the relevant kind" (p. 36). Winch further says that the knowing how also involves intentionality and normativity, essential features of human action and of any account of expertise.
} 
boat starts by firing up the engine and navigating the waters with the steering wheel, we should also be able to say that Bruno actually knows how to fire up the engine and how to navigate the waters with the steering wheel. Bruno's knowing how implies that his knowledge is not only through general principles, but also through experience and practice. This means that Bruno must somehow know how the different parts of the boat work, and what factors might affect the functionality of such parts. As in the case of Jane, her experience of the Milgram experiment should let her know that her disposition to be compassionate and her choice to be compassionate can be affected by situational factors. If she deliberated on her experience properly, she would now have an idea of how she would handle herself in similar situations so she would not act "out of character" next time.

Winch is not alone in saying that skills are not reducible to dispositions. Winch talks about skills and dispositions in general, but Zagzebski applies the same irreducibility to the analysis of virtue. She takes dispositions to mean habits formed from repeated choices. Also citing Ryle, she says that the formation of habits should only be secondary in our concern for virtue, because there are "higher-grade dispositions," like skills and virtues, that we should be more concerned with. ${ }^{44}$ Zagzebski maintains that virtues are not on the same plane as skills, but she nonetheless classifies both virtues and skills as higher-grade dispositions because they need intelligence in their functioning. Zagzebski further says that having the virtues does not mean having automatic behavioral responses since virtues are intelligent responses, and they are strongly connected to a motivational structure. ${ }^{45}$ This motivational structure, says Zagzebski, is what makes virtues "prior" to skills. ${ }^{46}$

${ }^{44}$ Gilbert Ryle, The Concept of Mind (London: Hutchinson, 1949), 42-4. Quoted in Linda Trinkaus Zagzebski, Virtues of the Mind: An Inquiry into the Nature of Virtue and the Ethical Foundations of Knowledge (Cambridge: Cambridge University Press, 1996), 117.

${ }^{45}$ Zagzebski, Virtues of the Mind. Nancy Snow echoes the existence of virtue's motivational structure in the fourth chapter of her book (op cit.). She claims that virtue is a form of "social intelligence." Virtue, as such, is a complex integration of cognitive and affective elements that are shaped by an individual's motivations. This suggests that the psychological state and motivational structure of a virtuous person is not unitary, but composed of separable but integrated "cognitive units" which affect the kind of behavior that $\mathrm{s} / \mathrm{he}$ will most likely manifest in a given situation. Snow builds up this notion of social intelligence from Nancy Cantor and John F. Kihlstrom's 1987 book, Personality and Social Intelligence. Cantor and Kihlstrom aims to explicate the notion of cognitive expertise in their book, specifically the notion of social intelligence which they define as a multifaceted and situation-flexible, albeit domain-specific form of intelligence. Under this notion, an individual can be intelligent in a certain social situation yet dysfunctional, or at least not perform as good as, in another. This has direct implications to virtue, as Snow have also shown, these implications will have to be pursued in a different essay.

$$
{ }^{46} \text { Ibid., } 116 .
$$


Annas also emphasizes on another kind of structure that separates skills from dispositions: the intellectual structure. She says that the least necessary requirement for virtue is to have "a disposition to do the right thing," but what likens it to a skill is its need for an intellectual structure. ${ }^{47}$ A genuinely skillful person - an expert-should have a "unified grasp" of her field of expertise, and also be able to "give an account" of why she does things the way she does. ${ }^{48}$ These two requisites for the expert are important because they demonstrate that the expert actually learned what she knows. The unified grasp of the field allows the expert to impart her knowledge to those who are trying to emulate her; while the account to be given serves as proof that she has deliberated on what she did and that the outcome of her action is not because of chance.

The need for intellectual structure in virtue and skills implies the need to learn or the need to understand that which is being developed, ${ }^{49}$ and the need for the motivational structure implies the drive to be better or the desire to live a life that can be considered as good. The choice and the effort entailed in the development of virtue make it very a personal affair. This means that the process of development does not end at being able to successfully emulate a moral exemplar, and neither does it end in being a moral exemplar yourself. The aspiration to improve and be better than what one has already achieved should always be present in a person trying to be an expert. ${ }^{50}$ This does not mean that expertise is unattainable; it only means that we should prevent our skills to relapse into a mere routine by developing it even further.

What we have seen so far is that dispositions, in themselves, are static and cannot bring about a change in one's character. Repeated choice to act in a coherent way is only about forming habits, and we should not concern ourselves too much with this, since there is a higher kind of ability that can actually bring about change in the person's character: skills. If we rely only on dispositions to characterize virtue, then people like Bruno can never be virtuous (which implies that we are "elitists" because only a few, select individuals can actually be virtuous). But if we look at virtue as a skill, then the possibility of people becoming (more) virtuous becomes higher (and more inclusive) because they are actively involved in the cultivation of their own characters. The degree of one's active involvement is basically what sets people's attempts to become virtuous apart from others, and to a certain extent, serves as the standard for judging which person is doing a good job in bettering herself and which one is not.

233.

${ }^{47}$ Julia Annas, “Virtue as a Skill,” International Journal of Philosophical Studies 3 (1995),

${ }^{48}$ Ibid., 232-3.

${ }^{49}$ Annas, Intelligent Virtue, 17.

${ }^{50}$ Ibid., 18. 
By thinking of virtues as skills, we are also introduced to a broader notion of character that includes not only personality traits, but also a motivational and an intellectual structure that are pertinent to the development and practice of virtue here pictured. I believe that the argument I have presented would be better supplemented by a more in-depth discussion of the kind of intelligence involved in virtue: social intelligence. Cantor and Kilhstrom were the first to develop the notion of social intelligence in their 1987 book, ${ }^{51}$ and Snow appropriated their discussion in her conception of virtue. In a nutshell, social intelligence is a complex and multidimensional set of knowledge and abilities that an agent strategically uses to effectively complete his/her goals or life tasks. ${ }^{52}$

I believe that the discussion on social intelligence would provide the necessary continuity between the ancient notion of virtue as concerned with one's life as a whole and our notion of personality as a complex system of "socialcognitive" or "cognitive-affective" units which affect the way we respond to situational features and internal stimuli. This notion of personality is also known as the cognitive-affective processing system (CAPS) theory of personality developed by Walter Mischel and colleagues ${ }^{53}$ is in line with the social-cognitive theory that Doris notes to be similar to and "not obviously incompatible" with his account of local traits. ${ }^{54}$ Despite the similarities in their approach, Doris maintains his distance from the social cognitivists. He notes that while both approaches see behavioral consistency under "usual situations," these approaches are different because a situationist would stress on the fragmentation of character and disorder through varying situations, while the social cognitivist would stress on coherence and order in similar situations. ${ }^{55} \mathrm{He}$ further says that the latter is ambitious because its proponents claim to have solved the problem of cross-situational consistency of behavior, and that it introduces multiple perspectives to which

${ }^{51}$ Nancy Cantor and John F. Kihlstrom, Personality and Social Intelligence (New Jersey: Prentice-Hall Inc., 1987).

${ }^{52}$ Snow, op cit., 63-98.

${ }^{53}$ It is better to consult Snow's book for a more informative account of the CAPS theory as she cites numerous works by Mischel and company regarding the subject. My understanding of the said theory is indebted to Snow's presentation of it.

${ }^{54}$ Doris, "Lack of Character," 77.

${ }^{55}$ Ibid., 76-85. Doris says that for social cognitivists, situations should be deemed similar psychologically and not merely nominally. The psychological similarity of the situation depends on the subject's own definition of the situation-the situation should be similar from the subject's perspective-as opposed to the nominal similarity which depends on the observer's perspective. The observer deems a situation similar on the basis of the presence or absence of features that can either be morally significant or insignificant. It is the presence of these morally insignificant features, like dimes or the presence of noise, which situationists claim to have a significant effect on a person's behavior. This brings us to another strand of the situationist critique, but we shall not go into it in this essay.

(C) 2013 Janina Angeli M. Magundayao

http://www.kritike.org/journal/issue 12/magundayao june2013.pdf

ISSN 1908-7330

\section{(cc) BY-NC}


behavior may be deemed as consistent. ${ }^{56} \mathrm{I}$ believe that the similarity between the two approaches can be extended into a kind of compromise between the two opposing camps of situationism and virtue ethics-if indeed it is possible to find a compromise between their positions_-and I believe that looking into the notion of social intelligence can facilitate that extension. This discussion, however, would have to be pursued in a different paper.

\section{Conclusion}

The two-fold argument here presented hopefully would have been enough to show that we should not give up on cultivating our character despite the fact that our behavior can be affected by situational factors. By showing that the ancient Greek notion of disposition as settled patterns of choice is different from its contemporary notion as inherent qualities in a person that produce a certain kind of behavior, I have argued that the situationist high bar argument against virtue ethics is founded on a conceptual confusion. To prevent us from falling into this confusion even further, I proposed that we think of virtue more as a skill than a disposition. Such analogy to skill allowed us to recover ancient Greek insights on virtue as involving intelligence in its determination of how one ought to behave in a given situation and as a constantly developing, rather than already developed, element of our character. The argument thus presented would be better supplemented by going into the notion of social intelligence, but that will have to be discussed in a separate paper.

Department of Philosophy, Ateneo de Manila University, Philippines

\section{References}

Annas, Julia, The Morality of Happiness (New York: Oxford University Press, 1993).

, "Virtue as a Skill," in International Journal of Philosophical Studies, 3:2 (1995), 227-243.

, "Being Virtuous and Doing the Right Thing," in Proceedings and Addresses of the American Philosophical Association, 78:2 (November 2004), 61-75.

, Intelligent Virtue (New York: Oxford University Press, 2011).

Aristotle, "Nicomachean Ethics," in Readings in Ancient Greek Philosophy: From Thales to Aristotle, ed. by S. Marc Cohen, Patricia Curd, and C.D.C.

56 Please see the previous note. It implies a kind of relativism in terms of the definition of similarity between situations, which in turn decides whether a person is acting consistently with this past decisions or not.

(C) 2013 Janina Angeli M. Magundayao

http://www.kritike.org/journal/issue 12/magundayao june2013.pdf

ISSN 1908-7330 
Reeve (Indianapolis/Cambridge: Hackett Publishing Company, Inc., 1995), 660-719.

Bem, Daryl J. and D.C. Funder, "Predicting More of the People More of the Time: Assessing the Personality of Situations," Psychological Review 85 (1978), 485-500. Quoted in Doris, John M., Lack of Character: Personality and Moral Behavior (Cambridge, Cambridge University Press, 2002).

Cantor, Nancy and John F. Kihlstrom, Personality and Social Intelligence (New Jersey: Prentice-Hall Inc., 1987).

Choi, Sungho, "Dispositional Properties and Counterfactual Conditionals," in Mind 117:468 (2008), 795-841.

Doris, John M, "Persons, Situations, and Virtue Ethics," in Nous 32:4 (1998), 504530.

, Lack of Character: Personality and Moral Behavior (Cambridge, Cambridge University Press, 2002).

Doris, John M. and Stephen P. Stich, "As a Matter of Fact: Empirical Perspectives on Ethics," in The Oxford Handbook of Contemporary Philosophy, ed. by Frank Jackson and Michael Smith (New York: Oxford University Press, 2005), 114-152.

Hartshorne, Hugh and Mark May, Studies in the Nature of Character vol. I: Studies in Deceit (New York: McMillan, 1928). Quoted in Doris, John M., Lack of Character: Personality and Moral Behavior (Cambridge, Cambridge University Press, 2002).

Kamtekar, Rachana, "Situationism and Virtue Ethics on the Content of our Character," in Ethics 114 (April 2004), 458-491.

McCrae Robert R. and Paul T. Costa, Jr., Personality in Adulthood: A Five Factor Theory Perspective, 2nd ed (New York and London: The Guilford Press, 2003).

Merritt, Maria W., "Virtue Ethics and the Situationist Personality Psychology," in Ethical Theory and Moral Practice 3 (2000), 365-383.

Milgram, Stanley, Obedience to Authority: An Experimental View (New York: Harper and Row, 1974).

Quine, Willard Van Orman, Word and object (Cambridge: Massachusetts Institute of Technology Press, 1960).

Ryle, Gilbert, The Concept of Mind (London: Hutchinson, 1949). Quoted in Zagzebski, Linda Trinkaus, Virtues of the Mind: An Inquiry into the Nature of Virtue and the Ethical Foundations of Knowledge (Cambridge: Cambridge University Press, 1996).

, "Knowing How and Knowing That: The Presidential Address," in Proceedings of the Arisototelian Society, New Series 46 (1945-1946), 116. 


\section{DISPOSITIONS AND SKILLS}

Sabini, John and Maury Silver, "Lack of Character? Situationism Critiqued," in Ethics 115:3 (April 2005), 535-562.

Slingerland, Edward, "The Situationist Critique and Early Confucian Virtue Ethics," in Ethics 121 (January 2011), 1-31.

Snow, Nancy E., Virtue as Social Intelligence: An Empirically Grounded Theory (New York and London: Routledge, 2010).

Stichter, Matthew, "Ethical Expertise: The Skill Model of Virtue," in Ethical Theory and Moral Practice 10 (2007), 183-194.

, "The Skill of Virtue," PhD diss., Bowling Green State University, 2007. $<$ http://etd.ohiolink.edu/send-pdf.cgi/Stichter\% 20Matthew\%20K.pdf?bgsu1181851300>.

"Virtue, Skills and Right Action," in Ethical Theory and Moral Practice 14 (2011), 73-86.

Winch, Christopher, Dimensions of Expertise: A Conceptual Exploration of Vocational Knowledge (London and New York: Continuum, 2010).

Zagzebski, Linda Trinkaus, Virtues of the Mind: An Inquiry into the Nature of Virtue and the Ethical Foundations of Knowledge (Cambridge: Cambridge University Press, 1996). 